Brit. J. vener. Dis. (1960), 36, 27.

\title{
UVEITIS, ARTHRITIS, AND NON-SPECIFIC GENITAL INFECTION*
}

BY

\author{
R. D. CATTERALL
}

General Infirmary, Leeds

This communication reports the results of an investigation into the aetiology of uveitis, which was recently carried out at the Institute of Ophthalmology in London. During the period from May, 1957, to December, 1958, 248 male patients attending the Institute for the first time have been investigated. All new male patients with uveitis, whether anterior or posterior, were examined, thus eliminating the possibility of selection. A detailed clinical history was obtained and a thorough physical examination performed. Prostatic fluid was obtained by prostatic massage and five separate unstained specimens were examined microscopically at once. A stained smear of the fluid was also examined. Culture plates for growing pleuropneumonia-like organisms and plates for aerobic and anaerobic cultures were inoculated with prostatic fluid and with the centrifuged deposit of urine. Detailed haematological studies and serological tests including a complement-fixation test for P.P.L.O. were also carried out. The Rose-Waaler differential sheep cell agglutination test was performed on sera from a large sample of the patients. Radiographs of the chest, sacro-iliac joints, hands, feet, and ankles were taken in each case.

The uveitis from which the patients suffered was divided into anterior, posterior, and generalized. These subdivisions were based on the findings of the ophthalmologist who first examined the patients when they attended the Institute, and, in cases of doubt, were determined by a further ophthalmolological examination.

The prostatic fluid was considered to be abnormal if clumps of pus were found in the specimens or if more than ten leucocytes were present in several $1 / 12$ th inch microscopic fields.

The criteria for the diagnosis of ankylosing spondylitis are well known and have been described

*Paper read to a combined MSSVD-I.U.V.D.T. meeting in London, October 16, 1959. in detail in many recent publications. No case was diagnosed as one of ankylosing spondylitis in this series unless definite bilateral sacro-iliac joint changes were present and the clinical findings supported the radiological evidence.

In this series the term Reiter's disease was used to describe a syndrome characterized by uveitis or conjunctivitis, arthritis of a characteristic distribution and evolution, and evidence of genito-urinary infection, often in the form of urethritis. There was no evidence to suggest that dysentery was a factor in causing any of the cases of Reiter's disease. A number of patients in the series presented with disease in which there was often a history of acute genital infection some years previously, subacute or chronic arthritis, and chronic prostatitis. These patients were considered to represent the chronic form of Reiter's disease and in some of them the acute phase of the genital infection had occurred in the past but had been unnoticed by them. The radiological changes of Reiter's disease have been thoroughly described by Murray, Oates, and Young (1958) and the criteria laid down by these authors were used throughout the series.

The term plantar fasciitis was used to describe a condition characterized by painful feet, usually with tenderness on the under surface of the heel and frequently associated with plantar spur formation

There was also a group of patients who showed the radiological changes of sacro-iliitis but no other abnormality in the $x$ rays. It is probable that these cases were examples of an early stage of the chronic type of Reiter's disease, or, in some instances, of an early ankylosing spondylitis. As there was some doubt to which group they belonged, it was considered advisable to classify them in a separate category as cases of atypical sacro-iliitis.

A total of 248 patients was subjected to these investigations, but complete assessment was only possible in 222 ; in the remaining 26 either one or 
more of the investigations was not performed or a specimen of prostatic fluid was not obtained.

Of the 222 patients assessed, 142 (64 per cent.) were found to have chronic prostatitis by the criteria already defined.

Anterior uveitis occurred in 150 cases. Of these 150 patients 108 ( 72 per cent.) had chronic prostatitis. The uveitis was considered to be generalized in 26 cases and evidence of chronic prostatitis was found in eighteen (69 per cent.) of them. Posterior uveitis was diagnosed in 28 cases and chronic prostatitis was found in only nine ( 32 per cent.). In a small group of cases re-examination of the eyes showed that the patient was not suffering from true uveitis. There were eighteen such patients and chronic prostatitis was found in seven of them (39 per cent.).

Chronic prostatitis was, therefore, a very common finding in patients with anterior uveitis and in those with generalized uveitis. It was much less common in patients with posterior uveitis and those with other types of eye disease, and its incidence in these cases was comparable with that found in a series of controls.

The controls consisted of 44 patients of the same age group, who were in-patients in the general surgical wards of the London Hospital and who were examined for chronic prostatitis. Thirteen (29 per cent.) were found to have chronic prostatitis and the fact that this incidence approximates closely to that found in patients with posterior uveitis and other types of eye disease underlines the undoubted significance of the high incidence of chronic prostatitis in those with anterior uveitis ( 72 per cent.).

Reiter's disease was diagnosed in 52 cases ( 23 per cent.). Ten patients were suffering from active urethritis when they were first examined but only two of them had noticed this. Prostatitis was present in all 52 cases. The uveitis was anterior in 45 cases and generalized in seven. Recurrent attacks of uveitis had occurred in forty of the cases.

Ankylosing spondylitis was found in 29 cases (13 per cent.). All of these patients had anterior uveitis and prostatitis was present in all of them. The uveitis was recurrent in 23 cases and the remaining six were suffering from first attacks.

Atypical sacro-iliitis and chronic prostatitis were found in fourteen patients ( 6 per cent.). All fourteen had anterior uveitis. In six the sacro-iliitis was completely asymptomatic and was only revealed by the radiographs. The chronic prostatitis was also symptomless, so that the only overt manifestation of the condition was the uveitis.

Plantar fasciitis was found in seven patients (3 per cent.). All seven suffered from anterior uveitis and chronic prostatitis was found in all of them.

Pleuropneumonia-like organisms were grown from the prostatic secretions in only 22 cases ( 10 per cent.). The aerobic and anaerobic cultures of the prostatic fluid gave no positive information. Streptococci, staphylococci, and diphtheroids were grown in many cases and $E$. coli in a few, but these organisms are usually regarded as contaminants of the male genito-urinary tract.

The Rose-Waaler differential sheep cell agglutination test was performed on sera from 175 consecutive patients in the series. The test was negative in 164 cases and positive in eleven ( 5 per cent.). The complement-fixation test for pleuropneumonia-like organisms was positive in 35 cases (16 per cent.), and the gonococcal complement-fixation test in 25 cases (11 per cent.). Haematological investigations did not reveal any constant abnormalities. The erythrocyte sedimentation rate was raised in 77 cases (35 per cent.), these being mainly cases of active Reiter's disease or ankylosing spondylitis.

From this survey it is evident that chronic genital infection in the form of prostato-vesiculitis is frequently associated with anterior uveitis in male patients. No such association was demonstrated in cases of posterior uveitis or other types of ocular disease where the incidence was the same as in a group of controls. Reiter's disease, which is known to be precipitated by genital infection, was a common finding amongst patients with anterior uveitis. Ankylosing spondylitis, which is usually accompanied by chronic prostato-vesiculitis, was also present in a significant proportion of the cases. These findings suggest the possibility that the prostato-vesiculitis is the common factor between the uveitis and the arthritis. It is well known that in some cases prostatic massage may produce an exacerbation of uveitis. Reiter's disease and ankylosing spondylitis have many features in common and in some cases a differential diagnosis between them may be difficult or impossible. Plantar fasciitis and atypical sacro-iliitis are also probably components of the same syndrome. It is tempting to consider these three types of arthritis and plantar fasciitis as manifestations of one disease which is caused by genital infection and of which anterior uveitis is a common component. Absolute proof of this hypothesis is lacking, although the evidence points strongly in that direction.

In this survey bacteriological and serological investigations failed to reveal a likely causative organism. No support was given to the suggestion that pleuropneumonia-like organisms are a possible cause of this condition. 


\section{Summary}

(1) 222 patients suffering from uveitis have been extensively investigated. 142 (64 per cent.) were found to have chronic prostatitis. 52 patients had Reiter's disease, 29 (13 per cent.) ankylosing spondylitis, fourteen ( 6 per cent.) atypical sacroiliitis, and seven ( 3 per cent.) plantar fasciitis.

(2) Bacteriological and serological investigations failed to reveal a likely causative organism.

(3) It is suggested that chronic prostato-vesiculitis is the common factor in a syndrome which includes anterior uveitis, Reiter's disease, ankylosing spondylitis, atypical sacro-iliitis, and plantar fasciitis.

\section{REFERENCE}

Murray, R. S., Oates, J. K., and Young, A. C. (1958). J. Fac. Radiol., 9. 37 .
Uvéite, artrite, et urétrite non-gonococcique

\section{Resumé}

(1) 222 malades atteints d'uvéite ont été sujets d'une enquête profonde. Une prostatite chronique fut trouvé chez 142 malades (64 pour cent.). On trouva la maladie de Reiter chez 52 malades (23 pour cent.); la spondylose rhizomélique chez 29 (13 pour cent.); le sacro-coxalgie atypique chez 14 (6 pour cent.) et une inflammation de l'aponévrose plantaire chez 7 malades ( 3 pour cent.).

(2) Des investigations bacteriologiques et sérologiques ne decelèrent aucun organisme étiologique.

(3) Il est suggeré que la prostato-vesiculite chronique est le constituant commun dans un syndrome qui comprend l'uvéite anterieure, la maladie de Reiter, la spondylose rhizomélique, la sacro-coxalgie atypique et l'inflammation de l'aponévrose plantaire. 